\title{
artigo] Ideários de mulher: história social, 0 corpo, a moda e as atividades fisicas em São Paulo no início do século passado
}

Social history: the body, the fashion and physical activities in São Paulo in the first years of the last century

\section{[ ANA CRISTINA ARANTES ]}

Professora doutora em História e Filosofia pela Faculdade de Educação

da USP, mestre em Educação Fisica pela EEFEUSP, especialista em História de

São Paulo pelo Instituto Histórico e Geográfico de São Paulo e professora de

História da Educação Fisica, Lazer e Esporte da UNIFIEO.

E-mail: anacris.arantes@ig.com.br

[81] [resumo] Este trabalho teve por objetivo analisar a relação entre a história social, 0 corpo, a moda e as atividades físicas da mulher da elite paulistana no primeiro quarto do século XX. Trata-se de uma pesquisa sociocultural, descritiva e qualitativa, cujos dados foram obtidos por meio de literatura geral e específica, livretos, artigos, teses e recursos iconográficos da época, de modo a elucidar qual era o ideário de corpo, moda e atividade física. A mulher da elite paulistana se espelhava nas mulheres européias, mas, ganhando espaços públicos pouco a pouco, foi desenvolvendo hábitos necessários para o desempenho das funções e da expectativa que a modernidade lhe impôs. Cada vez mais ativa, transitou no mundo social das festas e das reuniões noturnas, mas, de dia, praticava atividade física - ginástica - condizente com o ideário médico higienista e social da época.

\section{palavras-chave}

história social; corpo; moda; atividade física.

[abstract] This work had as objective to analyze the relation between social history, body, fashion, and the physical activities of the woman of the paulistana elite in the first twenty years of the last century. It's a social-cultural, descriptive and qualitative research, whose data were published by means of general and specific literature, booklets, articles, theses and iconographic resources, of the time, to elucidate which were the ideas of body, fashion and physical activity. The woman of paulistana elite looked at herself as the european ones. Gaining public spaces, little by little, developed necessary habits for the performance of the functions and expectations that was imposed to her by modernity. Being more and more and more active she "transited" the social world of the parties and night meetings, but during the day she practiced physical activity - gymnastics - according with the medical social hygienist and social ideas of the time.

[key words] social history; body; fashion; woman physical activities. 


\section{Palavras introdutórias}

A estética, considerada como uma subdisciplina da Filosofia, objetiva, em primeira instância, levantar, questionar e estabelecer critérios de valor ou julgamentos ligados ao belo para que se possa reconhecer um objeto como tal. Em um segundo ponto de vista, a estética pode reconhecer a obra como algo valoroso quanto à representação social, que possui aspecto concreto como inicial e 0 simbólico - mimesis - como final.

A estética também pode ser definida como um esforço para tornar um objeto cognoscivel, utilizando os aspectos acima citados que se auxiliam e se integram harmoniosamente. Ou ainda, como pontua Ajzenberg (2000), a estética ligada à arte pode ser considerada como um meio de comunicação denso, revelador, construtor, facilitador do diálogo entre 0 passado, o presente e o futuro.

Para a citada autora, a arte (e a estética), segundo a visão clássica, está ligada à beleza, ao verdadeiro, ao esplendor da verdade. 0 belo, portanto, lembra a luz e a luz lembra Deus. Se a moda e a aparência corporal de certa forma são vistas e apreciadas sob o prisma estético, algo ligado ao "agradável aos olhos", arrisca-se afirmar - guardadas as devidas proporções - que ambas podem ser avaliadas por meio de julgamentos semelhantes aos aplicáveis à arte.

A partir do século passado, à arte e à estética adicionaram-se "conteúdos" provenientes da sociologia e da cultura. A certa "inocência", a "tolerância", a "plasticidade" ou o "lirismo", inerentes às observações de até então, deixaram de existir, pois, se reconheceu que à arte pode ser agregado valor econômico ligada ao contexto social e cultural dentro dos quais ela é produzida.

\section{A estética, a moda e o corpo da mulher paulistana}

Segundo Costa (2002, p.12),

a figura da mulher na arte brasileira surge como uma imagem idealizada da qual fazem parte atributos diversos, beleza física, conformação saudável, formas generosas e maternais, um rosto meigo e sorridente, pureza que quando não revelada, vinha inscrita nas faixas em latim que acompanham os florões como bandeiras de procissões.
A pintura no caso revelava, com estilo bastante conservador, cenas da vida doméstica, relações de família, jovens românticas e meigas, como as de Almeida Júnior. Sedutoras, expressavam, valendo-se de gestos suaves e olhares profundos, toda sua natureza feminina. Elas "(...) assumem posturas intimistas como em Amoedo, ou incorporam funções sociais como em Zeferino Costa" (CASTRO, 2002, p. 93).

Essas referências foram conceitualmente alteradas ou substituídas em decorrência do processo civilizatório e da redefinição dos papéis e funções assumidos pelas mulheres no século XX. "Tirando" os corpos dos retratos artísticos, os devolvemos às ruas, às casas e ao imaginário social...

A partir do século XIX, como explica Priore (2000), o corpo feminino começa a movimentar-se em direção ao esporte no fim do Segundo Reinado e início da República, quando se intensificou a prática do culto ao corpo, que hoje, segundo alguns autores, pode ser vista como uma preocupação que atravessou todos os setores, classes sociais e faixas etárias.

"O sport antes condenado, tornara-se indicativo de mudanças. Nosso fim: a belleza". A beleza só pode coexistir com a saúde, com a robustez e com a força (grifo nosso), alardeava a obra. "A belleza feminina e a cultura physica em 1918" (PRIORE, 2000, p. 64). 0 culto ao corpo pode ser analisado sob dois prismas; um apóia-se em um discurso que analisa as questões inerentes à estética e o outro se fundamenta nos itens ligados à saúde e ao bem-estar (CASTRO, 1998), este último pode ser considerado como uma esfera de competência ligada à atividade física.

Embora os novos ares modernos "provoquem" certa mudança de comportamento, é muito importante ressaltar que a sociedade paulistana, sobretudo a elite, observou a prática da atividade física feminina de forma muito discreta, às vezes impeditiva. Mas arriscamos afirmar que quanto ao critério de escolha do exercício físico, da modalidade ou da atividade física a ser praticada era muito diversificado. Assim, a opção entre a 
ginástica, o "esporte", ou a dança esteve intimamente ligada a outras esferas da vida e da classe social à qual o indivíduo pertencia.

Marcadora de distinção social, ocupando posição fundamental na sua argumentação e construção teórica que coloca o consumo alimentar, cultural e a forma de apresentação incluindo-se o vestuário, artigos de beleza, higiene, cuidados e manipulação do corpo em geral como as três mais importantes maneiras de distinguir-se (dos demais), pois são reveladoras das estruturas mais profundas determinadas e determinantes dos hábitos. (CASTRO, 1998, p. 01)

Sobre corpo e estética, o referido autor esclarece o que o primeiro revela de maneira não explícita, certa objetivação do gosto, "expõe" conceitos, informa aos demais sobre a maneira como as diferentes pessoas entendem e praticam a estética. Essa objetivação do corpo inicia-se pela sua aparência: (a) dimensões - peso, estatura e compleição física, (b) pelas formas - redondas, flexíveis, retas e curvas e ainda, (c) pela sua conformação visível - que se expressa sob infinitas maneiras, revelando, ao mesmo tempo, toda uma relação do eu com seu corpo, ou seja, toda uma maneira de tratá-lo, de cuidá-lo, de nutri-lo, de mantê-lo, de despi-lo, de vesti-lo, a qual, por sua vez, revela (tal como uma fotografia), um ideário - às vezes inconsciente - das disposições do habitus do ser.

0 corpo sempre foi objeto de apreciação em todos os tempos e culturas. Sua representação é produto de um contexto, de uma visão de mundo, e em seu interior, de uma visão de pessoa. Entendendo, portanto, a sua definição como fruto de uma construção social e cultural, a maneira de concebê-lo e de representá-lo pode ser entendida como um somatório, nem sempre muito bem articulado, da construção simbólica, das conquistas científicas, de crenças, de processos criativos e estéticos (AJZENBERG, 2000).
Depois de séculos de restrição, de repressão corporal, a sociedade passou a viver a reconquista e o encantamento com o corpo. Esse movimento do culto ao corpo tem sido vivido (particularmente pelas mulheres), valendo-se das mais variadas formas de atividade física, de utilização de produtos de higiene e beleza e dos recursos da medicina, que, a partir do século passado têm tentado responder as demandas sociais na busca da saúde.

A saúde é vista como uma prática de autogestão que inclui o direito à afirmação da identidade, da independência, da autonomia, de poder exibir, ingerir, fixar, incluir, excluir, praticar diversos conceitos e atitudes que resultem, em última análise, em felicidade e auto-realização. Advoga-se o corpo como um componente central da realização humana e 0 eixo estruturador do ser existencial (AJZENBERG, 2000).

"O processo de criação da imagem pessoal é um fenômeno presente na cultura humana desde os tempos muito antigos. 0 nosso rosto é a parte do corpo que menos vemos e que pouco conhecemos. Por isso aprendemos a avaliar os outros, mirando-nos no olhar alheio. A aprovação ou reprovação que nele percebemos nos guia e nos dá a dimensão da nossa presença" (CASTRO, 2002, p. 99).

Com relação ao item corpo e modernidade, Sevcenko, citado em Castro (1988), escreve que o culto ao corpo é um traço característico da modernidade, da sociedade contemporânea.

"Com as novas funções sociais, um novo papel na divisão do trabalho e objetivos afetivos e existenciais diferentes, a mulher adota (um) outro modelo; as imagens românticas, graciosas e sensuais que já estiveram no imaginário de homens e muIheres no século XIX, mas que jamais puderam ser adotadas como estilo de vida, dada sua incompatibilidade com as relações vigentes" (CASTRO, 2002, p. 141).

Comentando sobre as funções sociais e a aparência, Bonadio (2007) diz: "As novas modas eram bem recebidas pela maioria das mulheres, mas causa- 
vam polêmica entre os conservadores que entendiam os cabelos curtos e a silhueta feminina como uma distorção do feminino e uma masculinização da mulher".

A idéia fundamental desse tempo é que existe uma necessidade imperiosa de valorizar o contemporâneo, reconfigurar 0 antigo, sem, entretanto, ter-se encontrado suficiente subsídio que oriente e que torne o novo algo concreto e plausível. Vive-se, pois, um estado incipiente, uma transição entre o embrionário e um conceito inacabado. Essa realidade pode refletir-se em todos os aspectos da vida humana, inclusive na arte, na estética, na moda e na visão de corpo.

As relações entre arte e corpo, ou os processos criativos que motivam a elaboração da corporeidade humana, estão inseridas nas contradições da vivência urbana. Na base do processo estão os debates sobre a contemporaneidade e as bases epistemológicas dessas discussões. (AJZENBERG, 2000)

Para a estudiosa, esse processo "instável" é uma das mais importantes características da atmosfera moderna que envolvia (também) São Paulo nos anos 1920.

Em relação ao trato corporal, expulso pela moda higienista, o espartilho foi aos poucos substituído pela cinta elástica feita com barbatanas e botões. Essa importante alteração na indumentária feminina fez com que esse instrumento de tortura, usado por meninas a partir dos 11 anos de idade, deixasse de afinar o torso, acentuando a cintura e causando deformações (MATTAR, 2004).

A idéia de que o corpo possui uma linguagem e essa deve ser vista como um reflexo (perfeito) das emoções representou uma inovação para a época.

No Brasil, especialmente em São Paulo, à moda das francesas, nos anos 1920, a mulher passou a locomover-se com maior desenvoltura nos espaços públicos. Essa locomoção pode ser observada (a) como ato de ampliar sua esfera de ação ou (b) ato de deslocar-se nos espaços físicos necessitando, dentre outros objetos, de sapatos adequados não deformantes (como acusou Delsarte na Europa) visto que "o andar constitui assim o elemento privilegiado (...). Ele é visto como sendo representativo da atitude corporal geral de uma mu-
Iher e símbolo maior de sua elegância. A manutenção da postura reta é fator distintivo" (SCHPUN, 1999, p. 95). A conquista do espaço (urbano) levou-a, obrigatoriamente a cuidar da sua saúde, da estética corporal, bem como a fazer uso dos artifícios que a moda e os figurinos importados ofereciam a ela. Assim sendo, 0 atendimento a este apelo inserido em um "cenário coletivo" requisitou da mulher paulistana atualização permanente. Desta forma, em São Paulo, grandes lojas vendiam artigos apresentados em suas vitrinas, além do serviço de entrega porta a porta. "As mulheres eram convidadas a conhecer o novo charme da "roupa pronta" comprada em lojas. Aos homens eram oferecidos novos goalgets para embelezarem seus automóveis e lambretas" (SANT'ANNA, s/d).

As saias foram encurtadas pelas modistas para que as senhoras pudessem, com facilidade, subir nos bondes e nos carros. As meias valorizaram as pernas e os tecidos pesados deram lugar aos macios que salientavam as curvas do corpo. As cabeças, por sua vez, foram ornadas por chapéus. Mas as mudanças não abarcaram somente as mulheres; gradualmente, os homens passam a usar colarinhos mais flexíveis e chapéus de feltro. No século XX, o desnudamento e a flexibilidade das roupas fizeram com que a aparência física fosse cada vez mais importante e, por isso, cuidar do corpo tornou-se uma grande necessidade, daí a implementação das atividades físicas (e adequação segundo as expectativas). Sant'anna (s/d), comentando sobre os esportes e as roupas, explicita: "Os esportes e as roupas de ambos os sexos sugeriam um novo modo de pensar; era preciso respeitar os próprios desejos e não se esquecer de cuidar do corpo" .

A partir dessa idéia surgiram roupas para serem usadas nas quadras dos clubes privados. Somado a estas, vieram os trajes de banho para serem vestidos inclusive nos dias passados no litoral. Além dos banhos de mar, escreve Laver (2001), outros "esportes" influenciavam 
a roupa comum das mulheres. Tal como a usada no tênis, no ciclismo e na patinação; a moda feminina do dia-a-dia precisava atender as demandas cotidianas que se impunham de modo a facilitar sua vida.

0 século $X X$, ou a era das revoluções, caracterizou-se por acontecimentos bastante significativos tais como, dentre outros, a revolução industrial e a tecnológica. 0 êxodo rural levou ao constante e intermitente abandono do meio agrário em favor das cidades, nas quais os homens se concentraram em formações urbanas centrais e às vezes precárias, onde aprenderam a viver em grandes coletividades. (CASTRO, 2002, p. 120)

Sob a égide da diversão e do entretenimento, uma série de hábitos físicos e sensoriais praticados desde o início do século na cidade foi revista, incorporada e sistematizada no cotidiano de seus habitantes na segunda década do século XX. Mas, quanto às roupas femininas usadas pouco tempo antes, Camargos (2001) relata:

"As curvas do corpo eram artificialmente realçadas por mecanismos engenhosos e incômodos, incluindo anáguas e anquinhas, debaixo das saias do vestido, que, na virada para o século XIX, adquiriu caudas majestosas. Os pés acomodavam-se com botinas de cano alto e os cabelos, compridos, eram presos sobre a cabeça encimada por um chapéu" (p. 30).

Com tez da cor do alabastro, a muIher, apesar do suplício da roupa, deveria caminhar com graça e desenvoltura. A vestimenta, linguagem simbólica, representava, em última análise, a situação e classe social a que pertencia. Portanto, o traje luxuoso e destituido de praticidade, demonstrava ausência de vínculo com qualquer atividade produtiva, evidenciando assim o perfilamento com um meio economicamente privilegiado.
"Em resumo [acrescenta e enriquece Priore, 2000], a roupa, signo ou símbolo, consagrava e tornava visíveis as clivagens e hierarquias, segundo um código garantido e perenizado pela sociedade e suas instituições. Na elaboração de sua aparência vestimentar, as classes dominantes procuraram, (desde) sempre, distanciar-se das camadas populares" (p. 53).

Gradualmente e muito articulada ao mundo fashion, a elite também acoIheu os preceitos médicos vigentes. Assim, a medicina agiu fortemente sobre esse corpo social e, valendo-se também das práticas motoras, objetivou o aprimoramento da saúde física e moral para completar os ideais eugênicos de regeneração e purificação de raça para todos (PACHECO E CUNHA s/d). Esses preceitos foram ditados mesmo sabendo-se que as recomendações ficavam muito distantes da mulher trabalhadora.

A Educação Física, relacionada à disciplina e à higiene, serviu como um meio de propiciar saúde individualizada e normatizadora do comportamento. Sua prática sistemática ofereceria a necessária padronização dos corpos, que assim passariam a funcionar adequando-se e moldando-se social e utilitariamente ao mercado de trabalho (MORA$E S$, 1997).

Ainda que ocorresse uma aproximação à modernidade e aos seus ditames e nesse movimento estavam incluídas as práticas motoras, sabe-se que sua introdução e aderência ocorreram de forma gradativa.

Entretanto, à exposição dos corpos femininos, os anos 1920 inauguram uma nova e decisiva fase na cidade. 0 corpo belo deveria ser exibido nas áreas públicas, nos clubes, nas associações, nas lojas e nos pouquíssimos salões de beleza que se inauguravam. De maneira concomitante, a medicina opinou e indicou a prática dos exercícios e da vida saudável, preservando a saúde expressa não somente por um corpo firme e jovem, mas fiscalizando toda a cidade e todas as suas instalações públicas atuando fortemente nas privadas também.

Essa recomendação de saúde pública e de higiene pessoal foi muito valorizada pela elite paulistana; tanto assim que, no Diário de São Paulo de 20 de novembro de 1877, a ela foram acrescidos os exercícios físicos agora recomendados 
como uma prática social que favorecia o desenvolvimento das capacidades físicas da população. 0 artigo alertava os leitores que "patinar é o exercício mais saudável, popular e fashionable da epocha: assegura um movimento necessário, fortalece os pulmões, e dá ao corpo toda uma graça e flexibilidade altamente desejáveis. Façamos tudo para que seja agora um SPORT PAULISTA" (SCHWARCZ, 1995, p. 15).

Homens e mulheres provenientes da oligarquia rural instalaram-se em São Paulo constituindo uma forma inédita de ocupar o espaço urbano. Os novos códigos de diferenciação social que incluíram boa apresentação física foram gradualmente exibidos com (certa) elegância e desenvoltura por ruas, confeitarias, igrejas e, posteriormente, clubes esportivos.

Versando sobre a apresentação e classe social, Schpun (1999) escreve: "0 medo da feiúra, que deve ser eliminada a qualquer preço do horizonte visual, acompanha uma aprendizagem da apresentação física" (p. 23).

A manutenção da beleza tornou-se um tema privilegiado no conjunto dos itens normativos dirigidos principalmente às mulheres, discursos que não se limitavam a incitar o trabalho sobre a beleza, mas que procuraram também limitar os excessos. Sobre os excessos, Schpun (1999) afirma que os "artifícios são aceitos como último recurso para esconder a feiúra; pois, além de não favorecer a ideologia do natural uma muIher maquiada demais pode ser confundida com uma prostituta" (p. 93). Ainda ligada às questões de aparência, a valorização da juventude foi considerada um critério fundamental de beleza e de poder de atração especialmente para as mulheres. Assim, a velhice feminina foi vista como algo muito negativo, pois "no conjunto de representação, as raras muIheres que envelhecem tornam-se por isso, muito infelizes (...) essa consciência amarga significa perda total de prestígio e afastamento social" (SCHPUN, 1999, p. 103). Portanto, era interessante que a mulher se mantivesse jovem, saudável e, se possivel, sedutora.

\section{"Nós somos a juventude,} nós somos o porvir"

Como o momento era o da modernidade, a ação representou um símbolo dos novos tempos. Disponibilidade, forma física e jovialidade tornaram-se parte do imaginário nacional. A nação nos anos 1920 precisava ser jovem e pujante - o exercício físico ou esporte pode ser entendido como a concretização desse ideal. Por dedução, as antigas estruturas e o velho mundo foram considerados indesejáveis. Nos anos 1920, a forma física tornou-se mais visível (observam-se os concursos de beleza) e a natureza dos sexos também foi respeitada de maneira a manter o dualismo natural.

Ainda sobre o dualismo natural, convém ressaltar que os meios de difusão da Educação Física, bem como suas práticas, sempre e de forma abundante, buscaram definir os corpos, particularmente os femininos. Fernando de Azevedo, citado em Schpun (1999), aponta: "Espera que a educação física produza no corpo das muIheres, efeitos (que ele mesmo chama de) "estéticos" (p. 38), favorecendo inclusive uma locomoção graciosa alvo de atenções e de vigilância uma vez que ela passou a ocupar espaços públicos" (SCHPUN,1999).

Discutindo sobre a ocupação dos espaços públicos e a aparência, é interessante comentar que a opulência corporal passou a ser vista como algo indesejável. Ligada ao excesso de apetite e à falta de limites, a obesidade foi vinculada ao enriquecimento ilícito, à imoralidade, aos prazeres mundanos, à falta de moderação e à decadência das elites. Somando e acrescentando, Schpun (1999) afirma: "A obesidade tornou-se para todos, sinal de inatividade, de improdutividade" (p.120). Nesse sentido, as práticas fisicas poderiam afastar a mulher desse pesado julgamento, pois "os novos tempos demandam pessoas ágeis, rápidas, prontas para agir " (p.109).

Assim, exercícios, caminhadas, massagens, enfim, os cuidados corporais, destinavam-se à manutenção da silhueta esbelta. Essas atividades estavam fundamentalmente dissociadas de toda e qualquer forma de trabalho físico manual praticado pela classe trabalhadora.

A ginástica, sempre indicada, conferia à praticante a manutenção da boa forma física, conservava a saúde, dava mais segurança pessoal, aumentava o autoconceito, favorecendo o espírito de decisão, o controle das forças físicas e psíquicas. Por ser "controladora" dos im- 
pulsos, parece ter sido também muito interessante para a época. A ginástica naquele tempo então "é completamente despida de competitividade, de agressividade, de desejo de vitória, ou seja, das emoções produzidas no jogo coletivo" (SCHPUN, 1999, p. 41).

Esclarecendo, escrevo que, de certa forma, existia "atividade física" (movimento), "para todos", entretanto, as práticas giminico desportivas deveriam guardar os critérios de gênero vigentes.

\section{Considerações finais}

0 ideário da modernidade europeu foi vivido também pela mulher paulistana especialmente a da elite. Valendo-se da mentalidade dos novos tempos, dos produtos e recursos que a tecnologia oferecia, a esposa, mãe e mulher pôde desfrutar de uma vida requintada com novas e atra- entes atividades sociais. A modernidade $\mathrm{e}$ todo o seu entorno, favoreceram certa extensão de ação. Ganhando espaços, ruas, lojas e vitrinas, a mulher da elite paulistana pôde apreciar, observar, comparar e criar um estilo próprio para sua vida.

Ainda que seguisse as (restritivas) orientações médico-higienistas da época, podia, com alguma autonomia, exercer suas funções e talvez arriscar atuar como cidadã.

A moda mais adequada à situação urbana, os exercícios físicos, mormente a ginástica, favoreceram certa tomada de consciência e a autovalorização, contribuindo para a melhor percepção de sua constituição física, da sua potencialidade e de atuação na polis.

Ainda que existam estudos na esfera sociocultural relativos à mulher, à moda, ao corpo e à atividade física, parece haver muitas lacunas e dados a serem pesquisados, sob a forma interdisciplinar, de modo a favorecer a compreensão do ideário social da época. Esses estudos poderão, por certo, nos auxiliar no entendimento dos costumes, algo muito

\section{REFERÊNCIAS}

AJZENBERG, E. Pós-modernismo - novas imagens de arqueólogos. Apostila do Curso História da Arte II: beleza e corpo. Escola de Comunicações e Artes. Universidade de São Paulo. Setembro, 2000. s.p.

Concepções clássicas do corpo - basar-sarx. Apostila do Curso História da arte II: beleza e corpo. Escola de Comunicações e Artes. Universidade de São Paulo. Setembro, 2000. s.p.

BONADIO, M. C. Moda pra ler. Entrevista Maria Claudia Bonadio. Blog view. Disponivel em: $<$ http// blogview.wordpress.com/2007/08/12/moda-praler>. Acesso em: 19 jul. 2008

CAMARGOS, M. Villa Kyrial - crônica da belle époque paulistana. São Paulo: SENAC, 2001.

CASTRO, A L "Culto ao corpo, modernidade e mídia". Educación Física y deportes. Ano 3, no 9. Buenos Aires: março, 1998.

CLUB ATHLÉTICO PAULISTANO. Um clube que cresceu com a cidade. Edição comemorativa do 70 aniversário. São Paulo: 1970

COSTA, C. A imagem da mulher - um estudo de arte brasileira. Rio de Janeiro: SENAC-Rio, 2002.

LAVER, J. A roupa e a moda - uma história concisa. São Paulo: Companhia das Letras. 2001.

MATTAR, D. 0 preço da sedução - do espartilho ao silicone. Catálogo da exposição. Itaú Cultural, maio, 2004

MORAES, E. V. O higienisno e a educação física brasileira. V Encontro de História do Esporte, Lazer e Educação Física. Maceió, 1997. Anais.

PACHECO, A. J. \& CUNHA JR, C. F. F. A mulher na educação física/esporte na década de 1920 no Brasi - em busca das resistências às concepções higienistas e eugênicas. s/p, s/d.

PRIORE, M. D. Corpo a corpo com a mulher - pequena história das transformações do corpo feminino no Brasil. São Paulo: SENAC, 2000.

SANTANNA, D. B. de. Representações sociais da liberdade e do controle de si. (scp). (sd).

SCHPUN, M. R. Beleza em jogo - cultura física e comportamento em São Paulo nos anos 20. São Paulo: SENAC, 1999.

SCHWARCZ, L K. M. Virando o vinte - cotidiano, imaginário, política. São Paulo 1870-1910. Governo do Estado de São Paulo, Secretaria de Estado da Cultura. Departamento de Museus e Arquivos. Casa da Rosas. Galeria dos museus. 1994/1995. 